\title{
Sudden cardiac death in the young (5-39 years) in the canton of Vaud, Switzerland
}

Fanny Hofer ${ }^{1}$, Florence Fellmann², Jürg Schläpfer ${ }^{3}$ and Katarzyna Michaud ${ }^{4 *}$

\begin{abstract}
Background: Sudden cardiac death (SCD) among the young is a rare and devastating event, but its exact incidence in many countries remains unknown. An autopsy is recommended in every case because some of the cardiac pathologies may have a genetic origin, which can have an impact on the living family members. The aims of this retrospective study completed in the canton of Vaud, Switzerland were to determine both the incidence of SCD and the autopsy rate for individuals from 5 to 39 years of age.

Methods: The study was conducted from 2000 to 2007 on the basis of official statistics and analysis of the International Classification of Diseases codes for potential SCDs and other deaths that might have been due to cardiac disease.
\end{abstract}

Results: During the 8 year study period there was an average of 292'546 persons aged 5-39 and there were a total of 1122 deaths, certified as potential SCDs in 3.6\% of cases. The calculated incidence is 1.71/100'000 person-years ( 2.73 for men and 0.69 for women). If all possible cases of SCD (unexplained deaths, drowning, traffic accidents, etc.) are included, the incidence increases to $13.67 / 100^{\prime} 000$ person-years. However, the quality of the officially available data was insufficient to provide an accurate incidence of SCD as well as autopsy rates. The presumed autopsy rate of sudden deaths classified as diseases of the circulatory system is $47.5 \%$. For deaths of unknown cause $(11.1 \%$ of the deaths), the autopsy was conducted in $13.7 \%$ of the cases according to codified data.

Conclusions: The incidence of presumed SCD in the canton of Vaud, Switzerland, is comparable to the data published in the literature for other geographic regions but may be underestimated as it does not take into account other potential SCDs, as unexplained deaths. Increasing the autopsy rate of SCD in the young, better management of information obtained from autopsies as well developing of structured registry could improve the reliability of the statistical data, optimize the diagnostic procedures, and the preventive measures for the family members.

Keywords: Sudden cardiac death, Autopsy rate, Death certification

\section{Background}

According to the World Health Organization (WHO), cardiovascular diseases are the leading cause of mortality in the world, accounting for $30 \%$ of deaths in 2008 [1]. According to the Swiss Federal Statistical Office (FSO), $33.8 \%$ of the $62^{\prime} 091$ deaths registered in 2012 were of cardiovascular origin [2]. The rate of cardiovascular mortality increases with age, but cardiac deaths can also concern younger populations [3].

\footnotetext{
*Correspondence: Katarzyna.michaud@chuv.ch

${ }^{4}$ University Center of Legal Medicine, Lausanne and Geneva, Rue du Bugnon 21, 1011 Lausanne, Switzerland

Full list of author information is available at the end of the article
}

Approximately half of the cardiac deaths in young individuals are sudden, and often occur in individuals considered to be in good health $[4,5]$. Up to $53 \%$ of the sudden deaths in children, teenagers and young adults remain unexplained, despite performing a complete autopsy; these deaths are often considered to be arrhythmic in nature, resulting from inherited channelopathies [6,7]. Most of these disorders cannot be detected through a regular autopsy, but only by performing post-mortem genetic analyses, a.k.a. molecular autopsies or screening the first-degree relatives for inherited cardiovascular diseases [6,8-13]. The identification of mutation carriers among the living family members allows for the 
prevention of potential premature deaths through the establishment of appropriate preventative measures [14].

The exact incidence of sudden death in young individuals remains unclear. According to the literature, the incidence of sudden death for individuals under 40 years of age is between 0.7 and 6.2/100'000 person-years [5,15-24]. The incidence of SCD in Switzerland is not currently known, and there are only few data available on this matter in central Europe.

The Council of Europe recommends that the cause of death be established if at all possible and strongly encourages the use of autopsy. An autopsy plays an essential role in determining the cause of death and allows for its verification in an objective way. It also enables the documentation of precise demographic statistical data.

The aim of the present work is to establish the incidence of SCD between 2000 and 2007 in the canton of Vaud, Switzerland among individuals from 5 to 39 years of age on the basis of statistical data. Additional aims are to evaluate the autopsy rate in this population, and to determine the percentage of autopsies, which confirmed the diagnoses of SCD.

\section{Methods}

\section{General considerations}

The Canton of Vaud is one of the 26 Swiss cantons. According to Swiss Statistics, in 2012 the Canton of Vaud had a population of 734' 356 inhabitants representing 9.1\% of the Swiss population $\left(8^{\prime} 039^{\prime} 060\right)$. The average population of individuals who aged between 5 and 39 years between 2000 and 2007 was of 292'546 inhabitants. In the canton of Vaud, the general practitioner who completes a death certificate has to determine if the death was natural, violent or undetermined. If the death is determined to be violent or undetermined, a medico-legal investigation is usually undertaken but does not systematically include an autopsy. A forensic autopsy is performed if the appropriate authorities deem it necessary. Familial consent is not required for a forensic autopsy. If the death is determined to be due to natural causes, a clinical autopsy can be performed with the consent of the living relatives. Several weeks after the death, the general practitioner who signed the death certificate is contacted by the Swiss Statistics Office and is asked to complete the medical certificate (page 53 of these recommendations) concerning the cause of death and any existing concomitant diseases [25]. Among others, the following questions are asked: 1) Was an autopsy performed? 2) If so, are the results available? and 3) If performed, did the autopsy confirm the previously determined cause of death? The general practitioner who signs the death certificate is not, however automatically informed if an autopsy was performed or not, especially in the forensic context. He or she rarely has access to forensic autopsy results, as they are usually transmitted only to judicial authorities. This being the case, the forensic pathologist who performed the autopsy is not automatically questioned about the results of the post-mortem investigations. At present the autopsy results are not required for statistical purposes, however, their integration into the statistical analyses is strongly encouraged as noted in the recommendations mentioned above, "if possible, the results of autopsy should be awaited before validation of the cause of death".

\section{Data}

This retrospective study relied on the gathering of statistical data from both the Cantonal Statistical Research and Information Service (SCRIS) and the University Institute of Social and Preventive Medicine (IUMSP) in the canton of Vaud, Switzerland from 2000 to 2007. The SCRIS provided general demographic statistical data on the total population, broken down into age groups and the cause of death. The IUMSP provided the information regarding the autopsies performed and was contacted by its website. The general statistical information was obtained from the website of Swiss Statistics.

\section{Methods}

Among the deaths classified according to the ICD-10 code, cases which might correspond to SCD were extracted. Our methodology is based on previous studies with all its inherent limitations $[5,17,20]$. The first group included the cases classified as "diseases of the cardiovascular system" (Table 1). The second group included deaths whose origins were unclear or unknown, with the ICD-10 codes R96, R98, R99 and R09.2 (Table 2). The third group included deaths due to transport accidents, and those caused by drowning and submersion. When using ICD-10 codes with transport accidents, it is important to keep in mind that it is often difficult to determine whether the death was directly related to the vehicle's driver or not. The incidence was established for the population of the defined age range between 2000 and 2007 in these 3 groups.

The percentage of autopsies conducted was calculated using the data obtained from the IUMSP for all the deaths occurring in individuals from 5 to 39 years of age in the canton of Vaud between 2000 and 2007, as well as within each subgroup. We also analysed to what extent the autopsy results were used to update statistical data.

The protocol of this study was evaluated by the Cantonal (Vaud) Ethics Committee on research involving humans. No consent was requested as study was performed retrospectively on anonymous data, which was in accordance with the existing law.

\section{Results}

40 deaths were classified as presumed SCDs related to the cardiovascular system. The main cause of death in 
Table 1 Deaths classified as diseases of the circulatory system

\begin{tabular}{|c|c|c|c|c|c|c|c|}
\hline & & \multicolumn{6}{|c|}{ Age } \\
\hline & & $15-19$ & $20-24$ & $25-29$ & $30-34$ & $35-39$ & $15-39$ \\
\hline \multirow[t]{8}{*}{ Men } & I21 Acute myocardial infarction & 1 & & 2 & & 8 & 11 \\
\hline & I33 Acute and subacute endocarditis & & & & 1 & 1 & 2 \\
\hline & 142 Cardiomyopathy & & 2 & 1 & & 2 & 5 \\
\hline & 146 Cardiac arrest & 1 & & & 1 & 3 & 5 \\
\hline & 148 Atrial fibrillation and flutter & & & 1 & & & 1 \\
\hline & 149 Other cardiac arrhythmias & & & & 2 & 1 & 3 \\
\hline & 150 Heart failure & & 1 & & & 1 & 2 \\
\hline & I51 Complications and ill-defined descriptions of heart disease & 1 & 1 & & & 1 & 3 \\
\hline \multirow[t]{5}{*}{ Women } & 121 Acute myocardial infarction & & & 1 & & & 1 \\
\hline & 140 Acute myocarditis & 1 & 1 & 1 & & & 3 \\
\hline & 146 Cardiac arrest & & 1 & & & & 1 \\
\hline & 149 Other cardiac arrhythmias & & 1 & & & 1 & 2 \\
\hline & 150 Heart failure & & & & 1 & & 1 \\
\hline Total & & 4 & 7 & 6 & 5 & 18 & 40 \\
\hline
\end{tabular}

Causes of death (number of cases) between 2000 and 2007 classified as diseases of the circulatory system that may potentially be sudden cardiac deaths among individuals from 5 to 39 years of age in the canton of Vaud, Switzerland. There were no deaths under the age of 15 (data received from SCRIS).

this group was "acute myocardial infarction", consisting of 12 cases. This cause is predominant among men from 35 to 39 years of age (8 cases). It is followed by cardiac arrest (6 cases), other cardiac arrhythmias (5 cases) and cardiomyopathies (5 cases) (Table 1). An autopsy was conducted for 19 (47.5\%) of the 40 deaths (Figure 1). An informative feedback concerning the autopsy results was available for only 4 cases (10\%), allowing the confirmation of the initially certified cause of death (Table 3).

The cause of death remained undetermined or unclear for 121 deaths that could possibly have been SCD (data received from SCRIS). These cases were more frequent in the 30 to 39 year age category $(74 / 121 ; 61 \%)$ (Table 2$)$.
According to data received from IUMSP, an autopsy was performed in $13.7 \%$ of cases in this category of deaths and the autopsy results enabled the confirmation only for 2 deaths registered in the statistical data (Table 3). It was unknown if an autopsy was performed or not in 94 cases $(75.8 \%)$ (Figure 2).

Table 3 lists also 140 selected cases that could have been potentially due to faintness or even SCD, leading to a loss of control of the vehicle. These deaths were followed by an autopsy in 39 cases (27.9\%), which enabled confirmation of the cause of death in 13 cases (33.3\% of autopsied cases). An autopsy was performed in 11 out of the 16 cases of drowning/submersions (68.8\%),

Table 2 Deaths classified as "deaths with ill-defined and unknown causes"

\begin{tabular}{|c|c|c|c|c|c|c|c|c|c|}
\hline & & \multicolumn{8}{|c|}{ Age } \\
\hline & & $5-9$ & 10-14 & 15-19 & $20-24$ & $25-29$ & $30-34$ & $35-39$ & $5-39$ \\
\hline \multirow[t]{4}{*}{ Men } & R09.2 Respiratory arrest & & 1 & & & 1 & 5 & 9 & 16 \\
\hline & R96.0 Instantaneous death & & & & & & 1 & & 1 \\
\hline & R98 Unattended death & & & & & & & 2 & 2 \\
\hline & R99 Other ill-defined and unspecified causes of mortality & 2 & 1 & 7 & 11 & 9 & 13 & 24 & 67 \\
\hline \multirow[t]{3}{*}{ Women } & R09.2 Respiratory arrest & & & & & 1 & 2 & & 3 \\
\hline & R98 Unattended death & & & & & & 1 & & 1 \\
\hline & R99 Other ill-defined and unspecified causes of mortality & & 1 & 3 & 5 & 5 & 10 & 7 & 31 \\
\hline Total & & 2 & 3 & 10 & 16 & 16 & 32 & 42 & 121 \\
\hline
\end{tabular}

Causes of death (numbers of cases) between 2000 and 2007 classified under to be due to "deaths with ill-defined and unknown causes" among individuals from 5 to 39 years in the canton of Vaud, Switzerland (data received from IUMSP). 


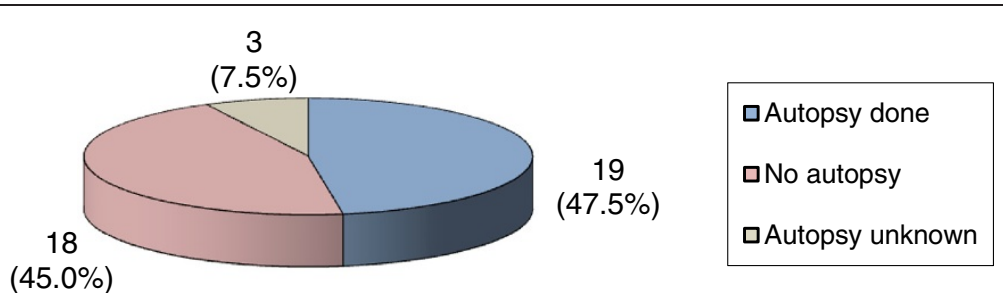

Figure 1 Autopsies for potential sudden cardiac deaths. Legend: Absolute Number and percent of autopsies for deaths considered as potential sudden cardiac deaths between 2000 and 2007 classified as "diseases of the circulatory system" among individuals from 5 to 39 years of age in the canton of Vaud, Switzerland (data received from IUMSP).

which confirmed the cause of death in 4 cases $(36.4 \%$ of autopsied cases) (Table 3).

\section{Incidence of presumed SCD between 2000 and 2007 among individuals from 5 to 39 years}

The calculated incidence of presumed SCD classified as diseases of the circulatory system is 1.71 per $100^{\prime} 000$ person-years. The incidence is greater for males than females (2.73 and 0.69/100'000 person-years, respectively). It remains possible, however, that some cases of presumed SCD were misclassified as "deaths of ill-defined and unknown causes" (i.e. R96, R98, R99 and R09.2). If these ICD-10 codes are included in the calculation, the incidence of SCD increases to 7.01/100'000 personyears.

If the transport accidents and the drownings/submersions that could have potentially been of cardiac origin are included, even if this appears very unlikely, the presumed incidence increases even further to $13.67 / 100^{\prime}$ 000 person/years. As already explained in the methodology section, it is difficult to ascertain whether the death was directly related to the vehicle's driver or not when using ICD-10 codes with transport accidents. It is also impossible to distinguish all possible primary causes of drowning on the basis of codified data. The presumed incidence varies by a factor 8 depending on which categories are considered. It is certain that all these deaths in the three categories are not SCDs, but it is difficult to determine to what extent.

\section{Discussion}

The reliability of the incidence depends on the available statistical data, which is based on the information given by the physicians who declare the deaths. We noted that the quality of the officially given data was insufficient to provide an accurate incidence of SCD as well as autopsy rates. Therefore we use the term of "presumed" considering this limitation inherent to the current system of codification and to the retrospective nature of the study. The calculated incidence of presumed SCD for the deaths in the group related to cardiovascular disease is $1.71 / 100^{\prime} 000$ person-years, and represents $3.6 \%$ of deaths among the studied population. These results are in accordance with those previously published in other

Table 3 Numbers and percent of autopsies and diagnosis confirmation among the different groups of causes of death that may be at the origin of a sudden cardiac death, among people aged from 5 to 39 between 2000 and 2007, in the Vaud Canton of Switzerland

\begin{tabular}{|c|c|c|c|c|c|}
\hline & $\begin{array}{l}\text { Cases } \\
\text { N (\%) }\end{array}$ & $\begin{array}{l}\text { Autopsy act } \\
\text { codified as } \\
\text { performed }\end{array}$ & $\begin{array}{l}\text { Autopsy act } \\
\text { codified as not } \\
\text { performed }\end{array}$ & $\begin{array}{l}\text { Unknown } \\
\text { if autopsy } \\
\text { was performed }\end{array}$ & $\begin{array}{l}\text { Cause of death } \\
\text { confirmed after } \\
\text { an autopsy }\end{array}$ \\
\hline All diseases of the circulatory system included & $71(6.3 \%)$ & $34(47.9 \%)$ & $32(45.1 \%)$ & $5(7.0 \%)$ & $14(41.2 \%)$ \\
\hline Diseases of the circulatory system, potential sudden deaths & $40(3.6 \%)$ & $19(47.5 \%)$ & $18(45.0 \%)$ & $3(7.5 \%)$ & $4(21.1 \%)$ \\
\hline Deaths by ill-defined and unknown causes & $124(11.1 \%)$ & $17(13.7 \%)$ & $13(10.5 \%)$ & $94(75.8 \%)$ & $2(11.8 \%)$ \\
\hline Transport accidents & $140(12.5 \%)$ & $39(27.9 \%)$ & $60(42.9 \%)$ & $41(29.3 \%)$ & $13(33.3 \%)$ \\
\hline Drowning/submersion & $16(1.4 \%)$ & $11(68.8 \%)$ & $4(25.0 \%)$ & $1(6.2 \%)$ & $4(36.4 \%)$ \\
\hline General/ all deaths & $1122(100 \%)$ & $352(31.4 \%)$ & $507(45.2 \%)$ & $263(23.4 \%)$ & 130 (36.9\%) \\
\hline
\end{tabular}

This table presents a synthesis of the main statistical data. In the left column, percents were calculated according to the total number of deaths (1'122 deaths). In the four right columns, percents are related to the total number of cases from the corresponding category except the last column (percentages calculated for autopsied cases). The group "transport accidents" includes deaths that may derive from a cardiac cause, or a SCD resulting in loss of control of the vehicle. Drowning/submersions are normally classified in the group "other external causes of mortality". The column on the very right includes those cases with feedback from the autopsy results, enabling confirmation of the cause of death (data received from IUMSP). It is possible that the percentage of autopsies with a confirmed cause of death could be higher if the autopsy results were neither not available nor considered during the codification process. 


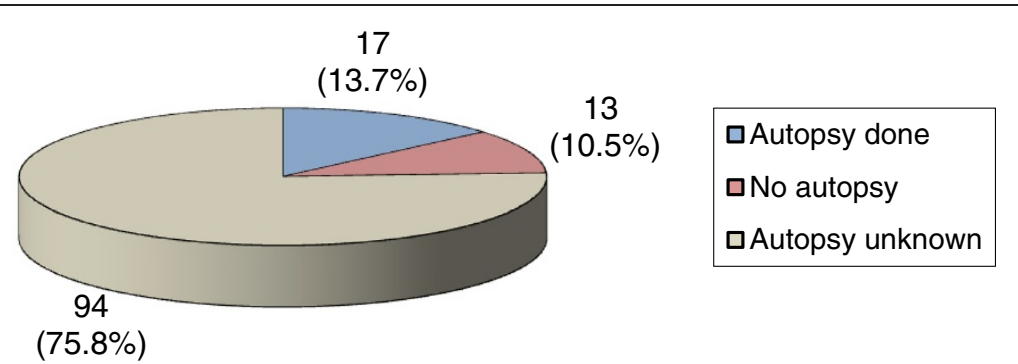

Figure 2 Autopsies for unexplained deaths. Legend: Absolute number and percent of autopsies for deaths between 2000 and 2007 classified as "ill-defined and unknown causes" among individuals from 5 to 39 years of in the canton of Vaud, Switzerland (data received from IUMSP).

countries [5,15-24,26-28]. A study conducted in England and in Wales showed an incidence of $1.8 / 100$ '000 personyears in a population between 1 and 34 years of age [20]. A Danish study calculated an incidence ranging from 1.9 to 2.8/100' 000 person-years among people from 1 to 35 years of age, depending on whether or not the non-autopsied cases were included [5]. A study conducted in Ireland in a population from 15 to 35 years of age, found an incidence of 2.85/100'000 person-years [17]. A Canadian study estimated an incidence of 2.6/100'000 person-years among individuals from 2 to 40 years of age [21]. A prospective study conducted on young Italian athletes from the Veneto region came up with an incidence of $2.1 / 100^{\prime} 000$ personyears. This same study estimated the incidence of nonathletes to be $0.7 / 100^{\prime} 000$ person-years [15] (Table 4). To our knowledge, data on the incidence of SCD among the young in Switzerland has never been published, nor for other populations of central Europe. As a result, we cannot compare our results to those from other parts of Switzerland, nor with some of the bordering countries.
We acknowledge the difficulty in determining a precise incidence of SCD due to the necessity to isolate, based on the ICD-10 codes, the cases of interest from all the other deaths caused by diseases of the circulatory system $[5,20]$. Furthermore, the ICD-10 codes do not indicate the continuity or the temporal links of the events leading up to death, leaving a lot of room for interpretation. A substantial number of deaths (11\%) were not classified under any defined cause (i.e. R96, R98, R99 and R09.2). This group could include cases of SCD, intoxications or other deaths that do not leave any visible trace for the practitioner conducting the summary examination upon declaring the death. The incidence based only on cases classified as cardiovascular deaths, excludes situations where a cardiac faintness could be at the origin of the fatal chain of events resulting in death, such as an epileptic crisis, drowning, or car accident $[20,29,30]$.

The global autopsy rate within the selected age group is $31.4 \%$. For deaths related to diseases of the circulatory

Table 4 Literature data and our study

\begin{tabular}{|c|c|c|c|c|c|c|}
\hline Country (region) & Study & Age, years & $\begin{array}{l}\text { Time period } \\
\text { of the study }\end{array}$ & $\begin{array}{l}\text { Incidence } \\
\text { n/100'000 }\end{array}$ & $\begin{array}{l}\text { Type(s) of } \\
\text { sudden deaths }\end{array}$ & $\begin{array}{l}\text { Studied } \\
\text { populations }\end{array}$ \\
\hline Canada (Ontario) & Pilmer [21] & $2-40$ & 2008 & 2.6 & SCD & General \\
\hline Ireland & Margey [17] & $15-35$ & 2005-2007 & 2.85 & SCD & General \\
\hline Denmark & Winkel [5] & $1-35$ & 2000-2006 & $1.9-2.8$ & SCD & General \\
\hline Greece (Epirus) & Fragkouli [16] & $1-35$ & 1998-2008 & 1.78 & SCD & General \\
\hline Ireland & Morris [19] & $14-35$ & 2005 & 3.18 & SCD & General \\
\hline Netherlands & Vaartjes [23] & $1-40$ & 1996-2006 & 2.07 & SD & General \\
\hline USA & Maron [27] & $8-39$ & 1980-2006 & 0.61 & SCD & Athletes \\
\hline England and Wales & Papadakis [20] & $1-34$ & 2002-2005 & 1.8 & SCD & General \\
\hline USA & Eckart [26] & $18-35$ & 1977-2001 & 13 & Non-traumatic SD & Military \\
\hline Spain (Bizkaia) & Morentin [18] & $1-35$ & 1991-1998 & 2.4 & $\mathrm{SD}$ & General \\
\hline Italy (Veneto) & Corrado [15] & $12-35$ & 1979-1999 & $0.7-2.1$ & SCD & Athletes vs non-athletes \\
\hline Sweden & Wisten [28] & $15-35$ & 1992-1999 & 0.93 & SCD & General \\
\hline England & Wren [24] & $1-20$ & 1985-1994 & 3.3 & SD & General \\
\hline USA (Minnesota) & Shen [22] & $20-40$ & 1960-1989 & 6.2 & $\mathrm{SD}$ & General \\
\hline Switzerland (Vaud Canton) & present study & $5-39$ & 2000-2007 & 1.71 & SCD & General \\
\hline
\end{tabular}

Incidence of sudden death among populations under 40 years old, SD (sudden death); SCD (sudden cardiac death). 
system that could potentially be a SCD, the autopsy percentage increases to $47.5 \%$. This autopsy rate in the canton of Vaud, Switzerland is low compared to that of other countries. This rate is astonishing, as the recommendations of the Council of Europe specify that an autopsy should be performed in every case of unexpected sudden death [31]. For instance, in Denmark, $75 \%$ of sudden unexpected deaths among people from 1 to 35 years of age undergo an autopsy and this percentage was thought to be far from optimal when the aim is to establish adequate statistics of the causes of death [5]. In Ireland, this rate is $86.3 \%$ for SCDs among those from 15 to 35 years of age [17]. In our population, the autopsy was conducted in only $13.7 \%$ of the cases with illdefined and unknown causes, which represent $11 \%$ of all the deaths. It was difficult, if not impossible, to determine the influence of the autopsy on the final classification of the cause of death. Thus, there is a substantial proportion of deaths of unknown cause with uncertain autopsy results. This group likely includes unrecognized SCDs, which will not undergo further investigation nor contribute to the data in the appropriate statistical group. We were surprised to find that the autopsy results often remained undisclosed, and were not included in the larger group of statistical data. The diagnosis was confirmed in only a relatively low proportion of cases (11.6\% of all cases and $36.9 \%$ of autopsied cases). When the diagnosis remained questionable or unconfirmed, it was impossible to determine if the cause of death was modified according to the post-mortem examination in the official published statistics.

The information obtained from the death certificates, which contains the basic information for the statistical analysis concerning mortality [9,32], differs between countries. In Denmark, the death certificate must be filled out by several individuals and contains a specific field for complementary information, such as circumstances of death, testimonies from witnesses and relatives, former medical conditions, a description of the external body examination and the preliminary conclusions before autopsy [5]. Despite the relatively high proportion of autopsies and the complementary information reported on the death certificate, the Danish register of statistics on the causes of death was considered insufficiently reliable by the authors of the study. They concluded that $24 \%$ of SCDs or unexplained sudden deaths were misclassified. Our study confirms that the use of death certificates in the statistical analysis of the causes of mortality is far from ideal as was already suggested by other authors $[9,32,33]$. It is of the utmost importance to find solutions to facilitate the coordination between the various individuals involved in the transmission of information, such as improving the feedback system and instructing medical students on how to correctly fill out death certificates [9] or developing structured registry of SCD in the young. The death certificate should be improved in order to provide more complete information about the circumstances of death, and to allow for easier and more representative codification. The solution will not be simple as it implicates several domains, such as medicinal, judicial and political. If the present situation is not improved the value of the published statistics on the causes of mortality will remain scientifically unreliable. Moreover, considering the genetic origin of many of SCDs, prevention of further deaths in family members without performing an autopsy will remain shackled.

\section{Conclusions}

This study is the first in Switzerland informing about the magnitude of SCD. The incidence of presumed SCD in the canton of Vaud, is comparable to the data published in the literature for other geographic regions but may be underestimated as it does not take into account other potential SCDs, as unexplained deaths. Better management of information obtained from autopsies and death certifications as well increasing the autopsy rate, developing structured registry of SCD in the young could improve the reliability of the statistical data. Autopsy findings are important not only to correctly codify the cause of death but also to optimize the diagnostic procedures and the preventive measures for the family members, considering the frequency of genetic diseases associated with sudden cardiac death.

\section{Limitations}

The limitations of the study are inherent to the retrospective review of data from our regional registries and low autopsy rate. However, the autopsy rate may be underestimated considering that the information concerning to whether an autopsy was performed or not, was unavailable in $23.4 \%$ of cases. The available anonymous data does not allow for the distinction between SCD and other cardiovascular deaths. For this reason the term "presumed SCD" has been chosen. Similar limitations have been reported in other published studies of this nature [9,32,33].

We think that our first evaluation of the magnitude of SCD in the canton of Vaud, Switzerland will be helpful to stimulate debate concerning the clinical implications of low autopsy rate in the young as of a lack of correlation between autopsy data and official statistics. We hope that our study will encourage further research in order to improve the situation.

\section{Abbreviations}

SCD: Sudden cardiac death; SCRIS: Cantonal statistical research and information service; IUMSP: University Institute of Social and Preventive Medicine; FSO: Swiss Federal Statistical Office.

\section{Competing interests}

The authors declare that they have no competing interests. 


\section{Authors' contributions}

$\mathrm{FH}$ carried the acquisition of data, has been involved in analysis and interpretation of data and in the drafting the manuscript. FF participated in the design of the study and has been involved in drafting and revising of the manuscript. JS has been involved in analysis and interpretation of data and revised the manuscript critically for important intellectual content. KM participated in the design of the study, participated and coordinated the data acquisition, and helped to draft the manuscript and in to its revision. All authors have read and approved the final manuscript.

\section{Acknowledgements}

We would like to thank Allison Felley, Sonia Barbosa and Luca Da Pare for editing the manuscript.

\section{Author details}

${ }^{1}$ University of Lausanne (UNIL), Faculty of biology and medicine, Lausanne, Switzerland. ${ }^{2}$ University Hospital of Lausanne, Service of Medical Genetics, 1011 Lausanne, Switzerland. ${ }^{3}$ Department of Cardiology, University Hospital of Lausanne, 1011 Lausanne, Switzerland. ${ }^{4}$ University Center of Legal Medicine, Lausanne and Geneva, Rue du Bugnon 21, 1011 Lausanne, Switzerland.

Received: 23 May 2014 Accepted: 3 October 2014

Published: 7 October 2014

\section{References}

1. WHO: Cardiovascular diseases: fact sheet. http://www.who.int/ mediacentre/factsheets/fs317/fr/index.html.

2. Swiss Statistics: Heath, key figures. http://www.bfs.admin.ch/bfs/portal/fr/ index/themen/14/01/key.html.

3. Swiss Statistics: Mortality, causes of death - data, indicators. http://www bfs.admin.ch/bfs/portal/fr/index/themen/14/02/04/key/01.html.

4. Virmani R, Burke AP, Farb A: Sudden cardiac death. Cardiovasc Pathol 2001, 10(6):275-282

5. Winkel BG, Holst AG, Theilade J, Kristensen IB, Thomsen JL, Ottesen GL, Bundgaard H, Svendsen JH, Haunso S, Tfelt-Hansen J: Nationwide study of sudden cardiac death in persons aged 1-35 years. Eur Heart J 2011, 32(8):983-990

6. Tester DJ, Ackerman MJ: The molecular autopsy: should the evaluation continue after the funeral? Pediatr Cardiol 2012, 33(3):461-470.

7. Hofman N, Tan HL, Clur S-A, Alders M, Van Langen IM, Wilde AAM: Contribution of inherited heart disease to sudden cardiac death in childhood. Pediatrics 2007, 120(4):e967-e973.

8. Michaud K, Fellmann F, Abriel H, Beckmann JS, Mangin P, Elger BS: Molecular autopsy in sudden cardiac death and its implication for families: discussion of the practical, legal and ethical aspects of the multidisciplinary collaboration. Swiss Med Wkly 2009, 139(49-50):712-718.

9. Pagidipati NJ, Gaziano TA: Estimating deaths from cardiovascular disease: a review of global methodologies of mortality measurement. Circulation 2013, 127(6):749-756

10. Campuzano O, Allegue C, Partemi S, Iglesias A, Oliva A, Brugada R: Negative autopsy and sudden cardiac death. Int J Legal Med 2014, 128:4-599. 606.

11. Michaud K, Mangin P, Elger B: Genetic analysis of sudden cardiac death victims: a survey of current forensic autopsy practices. Int J Legal Med 2011, 125(3):359-366.

12. Van der Werf C, Hofman N, Tan HL, Van Dessel PF, Alders M, Van der Wal AC, Van Langen IM, Wilde AAM: Diagnostic yield in sudden unexplained death and aborted cardiac arrest in the young: the experience of a tertiary referral center in The Netherlands. Heart Rhythm 2010, 7(10):1383-1389.

13. Behr ER, Dalageorgou C, Christiansen M, Syrris P, Hughes S, Tome Esteban MT, Rowland E, Jeffery S, McKenna WJ: Sudden arrhythmic death syndrome: familial evaluation identifies inheritable heart disease in the majority of families. Eur Heart J 2008, 29(13):1670-1680.

14. Raju H, Behr ER: Unexplained sudden death, focussing on genetics and family phenotyping. Curr Opin Cardio/ 2013, 28(1):19-25. doi:10.1097/ HCO.1090b1013e32835b32830a32839e.

15. Corrado D, Basso C, Rizzoli G, Schiavon M, Thiene G: Does sports activity enhance the risk of sudden death in adolescents and young adults? J Am Coll Cardiol 2003, 42(11):1959-1963.

16. Fragkouli K, Vougiouklakis T: Sudden cardiac death: an 11-year postmortem analysis in the region of Epirus, Greece. Pathol Res Pract 2010, 206(10):690-694.
17. Margey R, Roy A, Tobin S, O'Keane CJ, McGorrian C, Morris V, Jennings S, Galvin J: Sudden cardiac death in 14- to 35-year olds in Ireland from 2005 to 2007: a retrospective registry. Europace 2011, 13(10):1411-1418.

18. Morentin B, Suárez-Mier MP, Aguilera B: Sudden unexplained death among persons 1-35 years old. Forensic Sci Int 2003, 135(3):213-217.

19. Morris VB, Keelan T, Leen E, Keating J, Magee H, O'Neill JO, Galvin J: Sudden cardiac death in the young: a 1-year post-mortem analysis in the Republic of Ireland. Ir J Med Sci 2009, 178(3):257-261.

20. Papadakis M, Sharma S, Cox S, Sheppard MN, Panoulas VF, Behr ER: The magnitude of sudden cardiac death in the young: a death certificatebased review in England and Wales. Europace 2009, 11(10):1353-1358.

21. Pilmer CM, Porter B, Kirsh JA, Hicks AL, Gledhill N, Jamnik V, Faught BE, Hildebrandt D, McCartney N, Gow RM, Goodman J, Krahn AD: Scope and nature of sudden cardiac death before age 40 in Ontario: a report from the Cardiac Death Advisory Committee of the Office of the Chief Coroner. Heart Rhythm 2013, 10(4):517-523.

22. Shen W-K, Edwards WD, Hammill SC, Bailey KR, Ballard DJ, Gersh BJ: Sudden unexpected nontraumatic death in 54 young adults: a 30-year population-based study. Am J Cardiol 1995, 76(3):148-152.

23. Vaartjes I, Hendrix A, Hertogh EM, Grobbee DE, Doevendans PA, Mosterd A, Bots ML: Sudden death in persons younger than 40 years of age: incidence and causes. Eur J Cardiovasc Prev Rehabil 2009, 16(5):592-596.

24. Wren C, O'Sullivan JJ, Wright C: Sudden death in children and adolescents. Heart 2000, 83(4):410-413.

25. Statistique des causes de décès en Suisse: Directives concernant l'attestation médicale des causes de décès. http://www.iumsp.ch/ Publications/pub/DirCauseDeces_1991.pdf.

26. Eckart RE, Scoville SL, Campbell CL, Shry EA, Stajduhar KC, Potter RN, Pearse LA, Virmani R: Sudden death in young adults: a 25-year review of autopsies in military recruits.[see comment] [summary for patients in Ann Intern Med. 2004 Dec 7;141(11):I26; PMID: 15583219]. Ann Intern Med 2004, 141(11):829-834

27. Maron BJ, Doerer JJ, Haas TS, Tierney DM, Mueller FO: Sudden deaths in young competitive athletes. Circulation 2009, 119(8):1085-1092.

28. Wisten A, Forsberg $H$, Krantz $P$, Messner T: Sudden cardiac death in 15-35-year olds in Sweden during 1992-99. J Intern Med 2002, 252(6):529-536.

29. Büttner $A$, Heimpel $M$, Eisenmenger $W$ : Sudden natural death 'at the wheel': a retrospective study over a 15-year time period (1982-1996). Forensic Sci Int 1999, 103(2):101-112.

30. Oliva A, Flores J, Merigioli S, LeDuc L, Benito B, Partemi S, Arzamendi D, Campuzano O, Leung TL, Iglesias A, Talajic M, Pascali VL, Brugada R: Autopsy investigation and Bayesian approach to coronary artery disease in victims of motor-vehicle accidents. Atherosclerosis 2011, 218(1):28-32.

31. Brinkmann B: Harmonisation of medico-legal autopsy rules. Int $J$ Legal Med 1999, 113(1):1-14

32. Alfsen GC, Maehlen J: The value of autopsies for determining the cause of death. Tidsskr Nor Laegeforen 2012, 132(2):147-151.

33. James DS, Bull AD: Information on death certificates: cause for concern? J Clin Pathol 1996, 49(3):213-216.

doi:10.1186/1471-2261-14-140

Cite this article as: Hofer et al:: Sudden cardiac death in the young (5-39 years) in the canton of Vaud, Switzerland. BMC Cardiovascular Disorders 2014 14:140

\section{Submit your next manuscript to BioMed Central and take full advantage of:}

- Convenient online submission

- Thorough peer review

- No space constraints or color figure charges

- Immediate publication on acceptance

- Inclusion in PubMed, CAS, Scopus and Google Scholar

- Research which is freely available for redistribution 